\title{
Functional Abnormalities and Thyroid Nodules in Patients with End-stage Renal Disease
}

\author{
VANIA CUNA, VIOLA MENGHI, GIORGIA COMAI, MARIA CAPPUCCILLI, \\ GIUSEPPE CIANCIOLO, CONCETTINA RAIMONDI, FRANCESCO GRAMMATICO, \\ GABRIELE DONATI, OLGA BARALDI, IRENE CAPELLI and GAETANO LA MANNA \\ Department of Experimental Diagnostic and Specialty Medicine (DIMES), Nephrology, \\ Dialysis and Renal Transplant Unit, S. Orsola-Malpighi Hospital, University of Bologna, Bologna, Italy
}

\begin{abstract}
Background/Aim: Clinical and subclinical hypothyroidism is more common in patients with end-stage renal disease (ESRD) than in the general population. Patients with ESRD with hypothyroidism are more susceptible to cardiovascular disease, with an increased risk of mortality than those with normal thyroid function. Moreover, these patients have higher incidence of benign and malignant nodules. Patients and Methods: This was a retrospective study on 2,147 patients with ESRD on the renal transplant waiting list between 2000 and 2015 aimed at identifying the presence of hypothyroidism and associated variables. Results: Hypothyroidism was detected in 437/2,147 (20.3\%) patients, 289 of them having the subclinical form. Cardiovascular disease and older age were significantly associated with hypothyroidism, and autosomal polycystic kidney disease was correlated to goiter $(p<0.001)$. Conclusion: Thyroid abnormalities, particularly hypothyroidism with nodules, should be investigated in patients with ESRD on a waiting list for renal transplant to control cardiovascular complications and cancer risk.
\end{abstract}

Hypothyroidism is the most common disorder arising from thyroid hormone deficiency (1). Subclinical hypothyroidism is defined by a high serum concentration of thyroid-

This article is freely accessible online.

Correspondence to: Professor Gaetano La Manna, Department of Experimental, Diagnostic and Specialty Medicine (DIMES) Nephrology, Dialysis and Transplantation Unit S. Orsola-Malpighi Hospital, University of Bologna, Via G. Massarenti 9 (Pad. 15), 40138 Bologna, Italy. Tel: +39 0512144577, Fax: +39 051344439, e-mail: gaetano.lamanna@unibo.it

Key Words: Cancer, cardiovascular disease, end-stage renal disease, hypothyroidism, thyroid abnormalities, thyroid nodules, waiting list for renal transplant. stimulating hormone (TSH) with normal levels of free triiodothyronine (FT3) and tetraiodothyronine (FT4). Clinical and subclinical hypothyroidism is more common in patients with end-stage renal disease (ESRD) than in healthy individuals $(2,3)$, with a prevalence of $3-5 \%$ and $15-25 \%$, respectively versus 5-10\% of all forms of hypothyroidism in the general population $(5,6)$. In addition, the prevalence of hypothyroidism, especially the subclinical form, is increased in patients with lower estimated glomerular filtration rate (eGFR) (6). To date, no studies have demonstrated any nephropathy predisposing to the development of thyroid abnormalities, and the specific mechanism linking ESRD and thyroid dysfunction remains unknown (7). However, in renal patients, thyroid abnormalities are associated with an increased risk of cardiovascular complications with higher associated mortality as well as all-cause mortality. In particular, changes in myocardial systo/diastolic contractility, blood pressure $(8,9)$ and peripheral vascular resistance were detected together with an inhibition of vasodilator factors (10).

There is a substantial body of evidence to indicate the relationship between hypothyroidism and high incidence of vascular, valvular and coronary artery calcification (11-13). Low thyroid hormone levels (i.e. T3) have been associated with adverse cardiovascular sequelae in patients with chronic kidney disease and ESRD (8), but the underlying pathway involved remains largely unknown. It has been hypothesized that kidney disease may predispose to derangements of thyroid hormones due to nonthyroidal illness, malnutrition, inflammation, iodine retention, metabolic acidosis, medications, mineral deficiencies (e.g. selenium) and exposure to dialytic procedures (i.e. peritoneal effluent losses) $(1,8,14,15)$.

Vitamin D deficiency, a highly prevalent condition in patients with chronic kidney disease, whatever the degree of renal impairment, might play a role in thyroid disorders. Most of the biological actions of vitamin D are mediated by its binding to the nuclear vitamin $\mathrm{D}$ receptor and the activation of vitamin D receptor-responsive genes (16). 
Moreover, polymorphisms of vitamin D receptor gene have been found to affect susceptibly to autoimmune thyroid diseases (17-19).

Thyroid dysfunction can be correlated to the presence of structural abnormalities of the thyroid gland (diffuse goiter, multinodular goiter or single thyroid nodule). These changes may result from functional abnormalities or neoplasm. In patients with ESRD, benign and malign nodules are more common than in the general population (20-22).

This work was undertaken to investigate the spectrum of functional thyroid abnormalities and their possible associations with structural abnormalities of the thyroid gland and with clinical variables in a population of patients with ESRD on the kidney transplant waiting list.

\section{Materials and Methods}

Patients. From January 2000 to December 2015, this study included a cohort of 2,147 adult patients with ESRD (1,365 males, 782 females; age $=54.7 \pm 12.3$ years) on the waiting list for deceased donor renal transplant at our Kidney Transplantation Center.

Exclusion criteria were previous thyroid disorders, age $<18$ years, experience of thyroid dysfunction in the course of a critical clinical condition or sepsis, or non-thyroidal illness syndrome, therapy with amiodarone, propanolol or lithium, and thyroid dysfunction during pregnancy. The study also excluded those with colloid cysts, considering the following nodular lesions: one or more hypoechoic adenomatous nodules (not goiter); adenomatous goiter; primary thyroid carcinoma (papillary, follicular, medullar, undifferentiated); nodular lesions $>5 \mathrm{~mm}$ or nodules with malignant features diagnosed through fine-needle aspiration cytology.

The following general, anthropometric and clinical parameters were recorded to detect any associations with functional and structural thyroid abnormalities: gender, age, body mass index (BMI), primary causes of ESRD, type of treatment (hemodialysis $v s$. peritoneal dialysis or conservative therapy for pre-emptive transplantation), dialysis duration, time on waiting list, cardiovascular events (acute myocardical infarction or ischemic stroke, prior or during waiting time for transplant), presence of extra-thyroidal tumors, panel reactive antibody levels.

The co-presence of one or more thyroid-associated abnormalities was investigated to assess possible associations with one or more of the following clinical conditions: hypothyroidism/hyperthyroidism, autoimmune thyroiditis (AT), benign thyroid nodules, goiter or thyroid carcinoma.

We then compared the demographic and clinical characteristics between 437 ESRD patients with hypothyroidism, 24 with hyperthyroidism, and a control group consisting of 1,686 patients with ESRD with a normal thyroid function and without nodules.

The study was carried out in conformity with the Declaration of Helsinki. Due to its retrospective nature, registration or approval by the Ethics Committee was waived. Data were extracted from the patients' electronic medical records and the personal patientidentifying information was removed before analysis, in compliance with Italian Privacy Legislation (n. 196/2003).

Laboratory assays and definition of thyroid disease. A venipuncture blood sample was collected from each patient and serum TSH, FT4 and FT3 levels were assayed using an automated method (IMMUNOLITE 2000 analyzer; SIEMENS-DPC, Erlangen, Germany).

The diagnosis of hypothyroidism was based on the detection of serum TSH levels above $3 \mathrm{mU} / 1$, associated with reduced FT3/FT4 ratio, while the subclinical form was defined by suppression of TSH level with normal levels of FT3 and FT4.

To identify AT, the autoantibody profile was assessed by dosing anti-thyroperoxidase and anti-thyroglobulin $(23,24)$.

In addition to routine tests, the patients underwent ultrasound study of thyroid gland to rule out any nodules being associated with highrisk features.

Statistical analysis. Data are expressed as means \pm standard deviation for continuous variables, and percentage and absolute numbers for categorical variables. Statistical differences in the continuous variables were computed using the Student's $t$-test or the nonparametric Mann-Whitney $U$-test or two-way analysis of variance (ANOVA) followed by Bonferroni post-hoc test. Chi-square test was used in evaluation of the categorical variables. A $p$-value below 0.05 was considered as significant and all the statistical analyses were performed using SPSS (Statistical Package for Social Sciences, Chicago, IL, USA) for Windows version 16.0.

\section{Results}

Baseline data. This study evaluated 2,147 patients $(1,365$ males, 782 females) with ESRD on the waiting list for kidney transplant: $1,832(85.3 \%)$ were on the waiting list for their first kidney transplant, 295 (13.8\%) for their second, and $20(0.9 \%)$ for their third. Among them, 1376 patients $(80.9 \%)$ were under hemodialysis treatment, 405 (18.8\%) under peritoneal dialysis and six $(0.3 \%)$ were candidates for pre-emptive kidney transplant under conservative therapy. The mean patient age was $54.7 \pm 12.3$ years, ranging from 18 to 83 years. The mean waiting time on the list was $895.3 \pm 778.1$ days (for those patients waiting for second and third transplant, the time from restarting dialysis after previous transplant failure was considered). The mean time on dialysis was $480.2 \pm 780.4$ days.

The main primary cause of ESRD leading to kidney transplant were undiagnosed nephropathy in 30.5\%, autosomal-dominant polycystic kidney disease in ADPKD in $20.1 \%$, histologically diagnosed glomerulonephritis in $17.3 \%$, hypertensive nephrosclerosis in $10.1 \%$, tubulointerstitial nephropathy in $9.6 \%$, other hereditary kidney disease in $4.6 \%$, diabetic nephropathy in $3.2 \%$, vasculitis in $2.2 \%$, lupus nephropathy in $1.5 \%$ and other kidney diseases in $0.9 \%$.

The results of laboratory tests showed that $461(21.5 \%)$ patients had a thyroid abnormality: $437(20.3 \%)$ of them hypothyroidism ( $13.5 \%$ subclinical, $6.8 \%$ clinical), and 24 (1.1\%) hyperthyroidism ( $0.8 \%$ subclinical, $0.3 \%$ clinical).

Analysis of parameters after stratification for functional and structural thyroid abnormalities. Table I shows the demographic and clinical features of the total population of 
Table I. Demographic and clinical parameters in patients with euthyroidism ( $n=1686)$, hypothyroidism ( $n=437)$, and hyperthycroidism ( $n=24)$. Data are given as means \pm standard deviation (SD) for continuous variables, and absolute numbers with percentage in brackets for categorical variables. Statistical differences were computed using two-way analysis of variance followed by Bonferroni post-hoc test.

\begin{tabular}{|c|c|c|c|c|c|}
\hline & $\begin{array}{l}\text { Euthyroidism } \\
(\mathrm{n}=1,686)(\mathrm{A})\end{array}$ & $\begin{array}{l}\text { Hypothyroidism } \\
(\mathrm{n}=437)(\mathrm{B})\end{array}$ & $\begin{array}{l}\text { Hyperthyroidism } \\
\text { (n=24) (C) }\end{array}$ & $p$-Value & $\begin{array}{c}\text { Post-hoc } \\
\text { test }\end{array}$ \\
\hline Gender (female) & $598(35.5)$ & $170(38.9 \%)$ & $14(58.3 \%)$ & 0.033 & $\mathrm{~A}, \mathrm{~B}<\mathrm{C}$ \\
\hline Age, years & $54.0 \pm 12.3$ & $57.65 \pm 12.0$ & $52.8 \pm 9.8$ & $<0.001$ & $\mathrm{~A}, \mathrm{C}<\mathrm{B}$ \\
\hline BMI, $\mathrm{kg} / \mathrm{m}^{2}$ & $24.3 \pm 3.8$ & $24.4 \pm 3.7$ & $24.5 \pm 4.6$ & 0.863 & \\
\hline Time on dialysis, months & $15.8 \pm 26.4$ & $16.9 \pm 28.5$ & $14.2 \pm 22.1$ & 0.707 & \\
\hline \multicolumn{6}{|l|}{ Type of treatment } \\
\hline Hemodialysis & $1,366(81.0 \%)$ & $351(80.3 \%)$ & $19(79.2 \%)$ & & \\
\hline Peritoneal dialysis & $316(18.7 \%)$ & $84(19.2 \%)$ & $5(20.8 \%)$ & 0.992 & \\
\hline Pre-emptive & $4(0.2 \%)$ & $2(0.5 \%)$ & $0(0 \%)$ & & \\
\hline Days on waiting list & $896.3 \pm 776.63$ & $881.8 \pm 787.4$ & $1,062.1 \pm 983.2$ & $<0.001$ & $\mathrm{~A}, \mathrm{~B}<\mathrm{C}$ \\
\hline Maximum PRA, \% & $13.3 \pm 24.4$ & $14.6 \pm 25.3$ & $13.7 \pm 17.9$ & 0.614 & \\
\hline \multicolumn{6}{|l|}{ Cardiovascular disease } \\
\hline None & $1,613(95.7 \%)$ & $304(69.6 \%)$ & $20(83.3 \%)$ & $<0.001$ & $\mathrm{~B}<\mathrm{C}<\mathrm{A}$ \\
\hline One or more & $73(4.3 \%)$ & $133(30.4 \%)$ & $4(16.7 \%)$ & & \\
\hline History of cancer & $42(2.52 \%)$ & $21(4.5 \%)$ & $1(4.16 \%)$ & $<0.001$ & $\mathrm{~A}<\mathrm{B}, \mathrm{C}$ \\
\hline
\end{tabular}

BMI, Body mass index; PRA, panel reactive antibody.

2,147 patients with ESRD, divided into patients with euthyroidism $(n=1,686)$, patients with hypothyroidism $(n=437)$, and patients with hyperthyroidism $(n=24)$. The comparisons across the three groups revealed that female sex, age, time on waiting list, a previous history of cardiovascular events and of cancer were significantly associated with functional thyroid abnormalities (Table I).

We then focused the analysis on the group of 437 patients with hypothyroidism. Among them, 66 patients $(3.1 \%)$ had AT, with a higher frequency of females $(99.0 \%$ vs. $93.2 \%$, respectively; $p<0.001)$. Patients with AT were significantly younger $(49.3 \pm 12.5 v s .54 .9 \pm 12.3 ; p=0.001)$ and had a lower BMI $\left(22.3 \pm 3.2 v s .24 .4 \pm 3.7 \mathrm{~kg} / \mathrm{m}^{2} ; p<0.001\right)$. Moreover, the occurrence of at least one cardiovascular event was found to be less common in patients with thyroid autoantibodies than in those without AT (no cardiovascular event $3.4 \% \mathrm{vs}$. $96.6 \%$; one or more cardiovascular event $0.5 \%$ vs. $99.5 \%$; $p=0.022$ ).

The analysis of structural thyroid abnormalities in patients with hypothyroidism revealed that 200/437 (45.8\%) had a nodular disease, and in particular 120 out of $200(60 \%)$ had a single benign thyroid nodule, $53(26.5 \%)$ had a goiter and $27(13.5 \%)$ a neoplasm.

Moreover, the 437 patients with hypothyroidism were significantly older than the euthyroid controls, regardless of the presence or not of a nodule (hypothyroidism with nodular disease $v s$. hypothyroidism without nodular disease $v s$. euthyroid controls: $58.1 \pm 12.5$ vs. $57.1 \pm 11.5$ vs. $54.0 \pm 12.4$ years; $p<0.001$ ), had a longer time on waiting list (hypothyroid vs. euthyroid controls: $1092.4 \pm 874.0$ vs. $865.1 \pm 755.0$ days; $p=0.002)$, higher panel reactive antibody percentage (hypothyroid vs. euthyroid controls: $16.2 \pm 25.9 \%$ vs. $13.1 \pm 23.9 \%$; $p=0.018$ ), higher incidence of previous extrathyroidal cancer (hypothyroidism with nodular disease vs. hypothyroid without nodular disease $v s$. euthyroid controls: $5.1 \%$ vs. $8.5 \%$ vs. $2.1 \% ; p<0.001)$. The occurrence of at least one cardiovascular event was statistically associated with hypothyroidism, particularly in the presence of nodules (hypothyroidism with nodular disease vs. hypothyroidism without nodular disease vs. euthyroid controls: $35.9 \%$ vs. $24.0 \%$ vs. $4.3 \% ; p<0.001)$. Finally, we found a statistically significant association with female gender (female hypothyroidism with nodular disease vs. female hypothyroidism without nodular disease $v s$. female euthyroid controls: $30.4 \%$ vs. $49.0 \%$ vs. $35.5 \%$; $p<0.001$ ), and autosomal dominant polycystic kidney disease (ADPKD) as primary cause of ESRD (ADPKD hypothyroid with nodular disease $v s$. ADPKD hypothyroid without nodular disease $v s$. euthyroid controls: $15.6 \%$ vs. $37.0 \%$ vs. $18.7 \% ; p<0.001)$. In this last subgroup of hypothyroidic patients with ADPKD as primary nephropathy, the main structural abnormality of the thyroid gland was goiter $(41.5 \%)$.

Lastly, the whole patient population was divided according to the co-presence of the following three clinical risk conditions: Risk 1: defined by the presence of hypothyroidism or hyperthyroidism; risk 2 : defined by the presence of an AT; risk 3: defined by the presence of a nodule (benign or carcinoma). We compared patients with risk 1 and 2 and risk 1-3 with a control group of patients with ESRD without any risk. 
Table II. Comparisons for the main general and clinical features between patients of risk groups 1 and 2 and patients with no risk according to gender, type of treatment prior to kidney transplantation and occurrence of cardiovascular events. Risk 1: defined by the presence of hypothyroidism or hyperthyroidism; risk 2 , defined by the presence of autoimmune thyroiditis. Data are given as absolute numbers with percentage in brackets, and the statistical differences were computed the Chi-square test.

\begin{tabular}{lccc}
\hline & $\begin{array}{c}\text { Risk 1+2 } \\
(\mathrm{n}=481)\end{array}$ & $\begin{array}{c}\text { No risk } \\
(\mathrm{n}=1,666)\end{array}$ & $p$-Value \\
\hline $\begin{array}{l}\text { Gender (female) } \\
\text { Type of treatment }\end{array}$ & $200(41.6 \%)$ & $582(34.9 \%)$ & 0.008 \\
$\quad \begin{array}{l}\text { Hemodialysis } \\
\text { Peritoneal dialysis }\end{array}$ & $\begin{array}{c}381(79.2 \%) \\
98(20.4 \%)\end{array}$ & $\begin{array}{c}1355(81.3 \%) \\
307(18.4 \%)\end{array}$ & 0.504 \\
$\quad \begin{array}{l}\text { Pre-emptive } \\
\text { Cardiovascular diseases }\end{array}$ & $2(0.4 \%)$ & $4(0.2 \%)$ & \\
$\quad$ One or more & $137(28.5 \%)$ & $73(4.3)$ & $<0.001$ \\
\hline
\end{tabular}

Tables II and III show that female gender and the occurrence of cardiovascular events were more frequent in patients with hypothyroidism/hyperthyroidism and AT (risk 1 and 2) or with hypothyroidism/hyperthyroidism, AT and benign nodules, goiter or thyroid cancer (risk 1-3) compared to those without any risk.

\section{Discussion}

The link between kidney and thyroid function has been well known for many years (25-26). Hypothyroidism may affect renal function through direct (glomerular and tubular changes) and indirect (hemodynamic changes) mechanisms (27). In spite of the continuous improvement of dialysis technology and pharmacological treatments for ESRD, the impact of thyroid abnormalities on cardiovascular morbidity and mortality in renal patients has progressively emerged over the past decade $(8,28)$. The presence of hypothyroidism results in increased cardiovascular risk in patients with ESRD on a kidney transplant waiting list, a population with several cardiovascular risk factors $(8,26)$. Moreover, after transplant, cardiovascular immunosuppressive therapy exerts a detrimental effect on many cardiovascular risk factors and might further exacerbate cardiovascular risk $(29,30)$.

Our study evaluated functional thyroid abnormalities, in particularly hypothyroidism in a large cohort of adult Italian patients with ESRD waiting for kidney transplantation with a special emphasis on association with cardiovascular events. Here, subclinical hypothyroidism was identified by a TSH value $>3 \mathrm{mU} / 1$ with normal FT3/FT4 ratio. The target TSH level in dialysis patients is not well defined. Some studies suggest a range between 2.5 and $3.0 \mathrm{mU} / 1$, while some others
Table III. Comparisons for the main general and clinical features between patients of all risk groups and patients with no risk according to gender, type of treatment prior to kidney transplantation and occurrence of cardiovascular events. Risk 1: defined by the presence of hypothyroidism or hyperthyroidism; risk 2, defined by the presence of autoimmune thyroiditis. risk 3, defined by the presence of a nodule, benign or carcinoma. Data are given as absolute numbers with percentage in brackets, and the statistical differences were computed the Chi-square test.

\begin{tabular}{|c|c|c|c|}
\hline & $\begin{array}{l}\text { Risk } 1+2+3 \\
\quad(\mathrm{n}=964)\end{array}$ & $\begin{array}{c}\text { No risk } \\
(\mathrm{n}=1,183)\end{array}$ & $p$-Value \\
\hline Gender (female) & $400(41.5 \%)$ & $382(32.3 \%)$ & $<0.001$ \\
\hline \multicolumn{4}{|l|}{ Type of treatment } \\
\hline Hemodialysis & $784(81.3 \%)$ & $952(80.5 \%)$ & \\
\hline Peritoneal dialysis & $177(18.4 \%)$ & $228(19.3 \%)$ & 0.841 \\
\hline Pre-emptive & $3(0.31 \%)$ & $3(0.25 \%)$ & \\
\hline \multicolumn{4}{|l|}{ Cardiovascular disease } \\
\hline One or more & $166(17.2 \%)$ & $44(3.7 \%)$ & $<0.001$ \\
\hline
\end{tabular}

support the hypothesis that this value should be correlated with age/race/ethnic group parameters $(31,32)$. In our study, $21.4 \%$ of patients had abnormal values of laboratory tests indicating thyroid disorders, more commonly hypothyroidism. This finding is in line with previous evidence describing lower levels of total and FT3 in hemodialysis patients compared to the general population (3-7). On the other hand, hyperthyroidism was found in a low percentage of our cohort of patients with ESRD. However both hypothyroidism and hyperthyroidism were associated with a major cardiovascular event, and also with the presence of extra-thyroidal cancer. Female gender was a further risk factor for hyperthyroidism, while advanced age and ADPK were correlated with hypothyroidism.

We also analyzed hypothyroid patients with structural thyroidal abnormalities based on the presence or not of nodular disease (single benign thyroid nodule, goiter or neoplasia). Our results show that these patients have a higher incidence of cardiovascular events and neoplasm compared to those without structural thyroid abnormalities. The likelihood for a patient with hypothyroidism to receive a transplant appears to be reduced, as confirmed by our finding of longer waiting times on the transplant list. In this framework, we also found that the higher panel reactive antibody percentage represents a further unfavorable factor for their eligibility for transplant.

In our patients, hypothyroidism was found to be associated with ADPKD, and the main structural abnormality of thyroid gland was goiter. Although poor data are available about the correlation of thyroid abnormalities and ADPKD, a retrospective study by $\mathrm{Ha}$ et al. reported thyroid cysts in $6.7 \%$ of their series of 30 patients with ADPKD, attributing 
this finding to extra-kidney manifestation (33). Our study did not include cysts, but $41.5 \%$ of our patients with ADPKD had goiter. In view of these findings, thyroid nodules should be ruled out in patients with ADPKD.

Laboratory and instrumental data to evaluate thyroid function should be kept under consideration in patients with ESRD on a kidney transplant waiting list, especially hypothyroid patients with nodules who are at higher risk of cardiovascular complications and cancer and who should receive stricter monitoring.

\section{References}

1 Chaker L, Bianco AC, Jonklaas $\mathrm{J}$ and Peeters RP: Hypothyroidism. Lancet, Mar 20, 2017. http://dx.doi.org/ 10.1016/S0140-6736(17)30703-1

2 Schultheiss UT, Daya N, Grams ME, Seufert J, Steffes M, Coresh J, Selvin E and Köttgen A: Thyroid function, reduced kidney function and incident chronic kidney disease in a community-based population: the Atherosclerosis Risk in Communities study. Nephrol Dial Transplant, Aug 18, 2016. gfw301, https://doi.org/10.1093/ndt/gfw301

3 Targher G, Chonchol M, Zoppini G, Salvagno G, Pichiri I, Franchini M and Lippi G: Prevalence of thyroid auto-immunity and subclinical hypothyroidism in person with chronic kidney disease not requiring chronic dialysis. Clin Chem Lab Med 47: 1367-1371, 2009

4 Lin CC, Chen TW, Ng YY, Chou YH and Yang WC: Thyroid dysfunction and nodular goiter in haemodialysis and peritoneal dialysis patients. Perit Dial Int 18: 516-521, 1998.

5 Lo JC, Chertow GM, Go AS and Hsu CY: Increased prevalence of subclinical and clinical hypothyroidism in persons with chronic kidney disease. Kidney Int 67: 1047-1052, 2005.

6 Chongol M, Lippi G, Salvagno G, Zoppini G, Michele M and Giovanni T: Prevalence of Subclinical hypothyroidism in patients with chronic kidney disease. Clin J Am Soc Nephrol 3(5): 1296-1300, 2008

7 Jusufovic S and Hodzic E: Functional thyroid disorders are more common in patients on chronic hemodialysis compared with the whole population. Mat Soc Med 23(4): 206-209, 2011.

8 Rhee CM, Brent GA and Kovesdy CP: Thyroid functional disease: an under-recognized cardiovascular risk factor in kidney disease patients Nephrol Dial Transplant 30: 724-737, 2015.

9 Yao J and Eghbali M: Decreased collagen gene expression and absence of fibrosis in thyroid hormone-induced myocardial hypertrophy. Response of cardiac fibroblasts to thyroid hormone in vitro. Circ Res 71: 831-839, 1992.

10 Klein I and Danzi S: Thyroid hormone and the cardiovascular system. Med Clin North Am 96: 257-268, 2012.

11 Raggi P, Boulay A, Chasan-Taber S and Amin N, Dillon M, Burke SK and Chertow GM: Cardiac calcification in adult hemodyalisis patients. A link between end-stage renal disease and cardiovascular disease? J Am Coll Cardiol 39: 695-701, 2002.

12 Shantouf RS, Budoff MJ, Ahmadi N, Ghaffari A, Flores F, Gopal A, Noori N, Jing J, Kovesdy CP and Kalantar-Zadeh K: Total and individual coronary artery calcium scores as independent predictors of mortality in hemodialysis patients. Am J Nephrol 31: 419-425, 2010.
13 Kmiec P and Sworczak: Vitamin D in thyroid disorders. Exp Clin Endocrinol Diabetes 123(7): 386-393, 2015.

14 Cianciolo G, La Manna G, Colì L, Donati G, D’Addio F, Persici E, Comai G, Wratten M, Dormi A, Mantovani V, Grossi G and Stefoni S: 5-Methyltetrahydrofolate administration is associated with prolonged survival and reduced inflammation in ESRD patients. Am J Nephrol 28(6): 941-948, 2008.

15 Lo JC, Beck GJ, Kaysen GA, Chan CT, Kliger AS, Rocco MV, Li M, Chertow GM; FHN Study: Thyroid function in end-stage renal disease and effects of frequent hemodialysis. Hemodial Int, 2017. doi:10.1111/hdi.12527. [Epub ahead of print].

16 Morrone LF, Bolasco P, Camerini C, Cianciolo G, Cupisti A, Galassi A, Mazzaferro S, Russo D, Russo L and Cozzolino M: Vitamin D in patients with chronic kidney disease: a position statement of the Working Group "Trace Elements and Mineral Metabolism" of the Italian Society of Nephrology. J Nephrol 29(3): 305-328, 2016.

17 Feng M, Li H, Chen SF, Li WF and Zhang FB: Polymorphisms in the vitamin $\mathrm{D}$ receptor gene and risk of autoimmune thyroid diseases: a meta-analysis. Endocrine 43(2): 318-26, 2013.

18 Wang X, Cheng W, Ma Y and Zhu J: Vitamin D receptor gene FOKI but not TAQI, APAI, BSMI polymorphism is associated with Hashimoto's thyroiditis: a meta-analysis. Sci Rep 7: 41540, 2017.

19 Inoue N, Watanabe M, Ishido N, Katsumata Y, Kagawa T, Hidaka $Y$ and Iwatani Y: The functional polymorphisms of $V D R, G C$ and $C Y P 2 R 1$ are involved in the pathogenesis of autoimmune thyroid diseases. Clin Exp Immunol 178(2): 262-269, 2014.

20 Yılmaz Akçay E, Tepeoğlu M, Özdemir BH, Özgün G, Kazancı $\mathrm{S}$ and Haberal M: Pretransplant thyroid findings in patients with end-stage renal disease. Exp Clin Transplant 14(Suppl 3): 67-70, 2016.

21 Da Costa AB, Pellizzari C, Carvalho GA, Sant'Anna BC, Montenegro RL, Zammar Filho RG, Mesa Junior CO, Hauck Prante PR, Olandoski M and Carvalho M: High prevalence of subclinical hypothyroidism and nodular thyroid disease in patients on hemodialysis. Hemodial Int 20(1): 31-37, 2016.

22 Sanai T, Okamura K, Inoue T, Abe T, Tsuruya K and Node K: Ultrasonographic detection of thyroid nodules in hemodialysis patients in Japan. Ther Apher Dial 14(3): 323-327, 2010.

23 Oncul A, Ates I, Arikan MF, Yilmaz N, Topcuoglu C, Yilmaz FM and Altay M: The relationship between procalcitonin and thyroid autoantibodies in patients with autoimmune thyroiditis. J Clin Lab Anal, 2017. doi: 10.1002/jcla.22123. [Epub ahead of print].

24 Grani G, Carbotta G, Nesca A, D’Alessandri M, Vitale M, Del Sordo M and Fumarola A: A comprehensive score to diagnose Hashimoto's thyroiditis: a proposal. Endocrine 49(2): 361-365, 2015.

25 Bradley SE, Stéphan F, Coelho JB and Réville P: The thyroid and the kidney Kidney Int 6(5): 346-365, 1974.

26 Katz AI, Emmanouel DS and Lindheimer MD: Thyroid hormone and the kidney. Nephron 15(3-5): 223-249, 1975.

27 Inglesias P, Bajo MA, Selgas R and Diez JJ: Thyroid dysfunction and kidney disease: An update. Rev Endocr Metab Disord 18(1): 131-144, 2017.

28 Colì L, La Manna G, Comai G, Ursino M, Ricci D, Piccari M, Locatelli F, Di Filippo S, Cristinelli L, Bacchi M, Balducci A, Aucella F, Panichi V, Ferrandello FP, Tarchini R, Lambertini D, Mura C, Marinangeli G, Di Loreto E, Quarello F, Forneris G, 
Tancredi M, Morosetti M, Palombo G, Di Luca M, Martello M, Emiliani G, Bellazzi R and Stefoni S: Automatic adaptive system dialysis for hemodialysis-associated hypotension and intolerance: a noncontrolled multicenter trial. Am J Kidney Dis 58(1): 93-100, 2011.

29 Kasiske BL, Snyder JJ, Gilbertson D and Matas AJ: Diabetes mellitus after kidney transplantation in the United States. Am J Transplant 3: 178-185, 2003.

30 Weaver DJ Jr., Selewski D, Janjua H and Iorember F: Improved cardiovascular risk factors in pediatric renal transplant recipients on steroid avoidance immunosuppression: a study of the Midwest Pediatric Nephrology Consortium. Pediatr Transplant 20: 59-67, 2016.

31 Baloch Z, Carayon P, Conte-Devolx B, Demers LM, FeldtRasmussen U, Henry JF, LiVosli VA, Niccoli-Sire P, John R, Ruf J, Smyth PP, Spencer CA, Stockigt JR; Guidelines Committee, National Academy of Clinical Biochemistry: Laboratory
Medicine Practice Guidelines. Laboratory support for the diagnosis and monitoring of thyroid disease. Thyroid 13(1): 3126, 2003.

32 Surks MI and Buoicai L: Age-and race-based serum thyrotropin reference limits. J Clin Endocrinol Metab 95(2): 496-502, 2010.

33 Ha SK, Park CH, Kna JS, Lee SY, Lee JI, Kim SJ, Seo JK, Lee HY and Han DS: Extrarenal manifestations of autosomal dominant polycystic kidney disease. Yonsei Med J 38(2): 111116, 1997.
Received August 19, 2017

Revised September 14, 2017

Accepted September 19, 2017 